\title{
Hypertensive response to exercise: mechanisms and clinical implication
}

Darae Kim and Jong-Won $\mathrm{Ha}^{*}$

\begin{abstract}
A hypertensive response to exercise (HRE) is frequently observed in individuals without hypertension or other cardiovascular disease. However, mechanisms and clinical implication of HRE is not fully elucidated. Endothelial dysfunction and increased stiffness of large artery contribute to development of HRE. From neurohormonal aspects, excess stimulation of sympathetic nervous system and augmented rise of angiotensin II seems to be important mechanism in HRE. Increasing evidences indicates that a HRE is associated with functional and structural abnormalities of left ventricle, especially when accompanied by increased central blood pressure. A HRE harbors prognostic significance in future development of hypertension and increased cardiovascular events, particularly if a HRE is documented in moderate intensity of exercise. As supported by previous studies, a HRE is not a benign phenomenon, however, currently, whether to treat a HRE is controversial with uncertain treatment strategy. Considering underlying mechanisms, angiotensin receptor blockers and beta blockers can be suggested in individuals with HRE, however, evidences for efficacy and outcomes of treatment of HRE in individuals without hypertension is scarce and therefore warrants further studies.
\end{abstract}

Keywords: Hypertension, Exercise

\section{Background}

Systolic blood pressure (BP) normally rises with exercise as cardiac output increases during exercise in responses to the increased demand of oxygen from working muscles via increased sympathetic tone. However, some individuals present with abnormally exaggerated rise in systolic BP during exercise. This phenomenon is known as a hypertensive response to exercise (HRE). Yet, there is no consensus about exact value of systolic BP to define a HRE. Previous studies defined HRE as a difference between peak and baseline systolic BP at least $60 \mathrm{mmHg}$ in men and at least $50 \mathrm{mmHg}$ in women during exercise testing or systolic BP exceeding the $90^{\text {th }}$ percentile (approximately a systolic $\mathrm{BP}>$ $210 \mathrm{mmHg}$ in men and $>190 \mathrm{mmHg}$ in women) [1-3].

A HRE is often observed in individuals without known cardiovascular diseases. Although it is generally considered as an abnormal response, there are conflicting data regarding its clinical significance. Some studies suggest that a HRE is associated with future development of

\footnotetext{
* Correspondence: jwha@yuhs.ac

Cardiology Division, Severance Cardiovascular Hospital, Yonsei University College of Medicine, 50 Yonsei-ro, Seodaemun-gu, Seoul 120-752, Republic of Korea
}

(c) 2016 The Author(s). Open Access This article is distributed under the terms of the Creative Commons Attribution 4.0 International License (http://creativecommons.org/licenses/by/4.0/), which permits unrestricted use, distribution, and reproduction in any medium, provided you give appropriate credit to the original author(s) and the source, provide a link to the Creative Commons license, and indicate if changes were made. The Creative Commons Public Domain Dedication waiver (http://creativecommons.org/publicdomain/zero/1.0/) applies to the data made available in this article, unless otherwise stated. hypertension and predict cardiovascular mortality [4-6], while others have not found such associations $[7,8]$. In this review, we aimed to describe possible pathophysiologic mechanisms of HRE and its clinical implications.

\section{Mechanisms of hypertensive response to exercise}

Although pathophysiology of HRE has not been fully understood, there are plausible mechanisms to explain this phenomenon. From a mechanistic point of view, a HRE can be explained by impairment of exercise induced endothelial vasodilation $[9,10]$. Endothelium-dependent vasodilation in conduit arteries occurs in response to systolic wall sheer stress during exercise. Impaired endothelial function may limit vasodilation in response to increased shear stress from exercise, therefore, result in HRE. Indeed, Wilson et al. [11] showed significantly higher peripheral resistance at all stages of exercise observed in normotensive individuals with HRE. Consistent with previous studies, Stewart et al. [10] demonstrated an independent correlation between flow mediated dilation and exercise BP in normotensive population, suggesting that impaired endothelial vasodilation may contribute to exercise hypertension. Reduced nitric oxide (NO) activity was demonstrated 
in patients with HRE, even in young subjects without overt cardiovascular risk factors [12].

While the impairment of endothelial function mainly contributes to HRE in younger individuals, arterial stiffness should be considered as the mechanism of HRE in older population. Increased arterial stiffness in elderly results in a reduction in arterial compliance, followed by a reduction of buffering capacity of BP, and finally lead to an abnormal increase in BP during exercise. Although a few studies report conflicting data, previous studies demonstrated positive association of HRE with large artery stiffness, assessed by pulse wave velocity, central pulse pressure, and mean arterial pressure [13].

During exercise, sympathetic nervous system and renin-angiotensin-aldosterone system (RAAS) play an important role, mediating heart rate and BP increments in normal healthy population $[11,14,15]$. We have demonstrated that augmented rise of angiotensin II during exercise in individuals with HRE when compared to age and gender matched control group with normal BP reactivity during exercise [1]. Plasma epinephrine and norepinephrine also increased in both groups of individuals with HRE or normal response during exercise. However, there was no significant difference between two groups. Augmented rise in angiotensin II in HRE group was consistently reproduced in following studies, although extents of increased levels were not the same, possibly due to different magnitude of exercise and sensitivity of measurements [12]. Importance of angiotensin II in HRE is also evidenced by a significant reduction of peak systolic BP during exercise with angiotensin II receptor blocker [16].

Other possible mechanisms, such as an abnormal glucose metabolism, insulin resistance, or endothelium derived hyperpolarizing factors, were suggested although investigated in a limited number of patients $[17,18]$.

\section{Clinical implication}

Deleterious effects of HRE on structure and function of left ventricle (LV) has been reported consistently. Theoretically, individuals with HRE would be exposed to abnormally high pressure loads to left ventricle (LV), which may result in global subendocardial ischemia due to mismatch between demand and supply from excessive rate-pressure stress. Indeed, a previous study demonstrated a greater likelihood of new or worsening abnormalities of wall motions from echocardiography in individuals with HRE, even in the absence of angiographically significant coronary artery stenosis [19].

Many of previous studies demonstrated increased LV mass index and stiffness in HRE, evidenced by higher prevalence of LV hypertrophy and diastolic dysfunction from echocardiography [20-22]. However, it should be noted that some studies reported conflicting data, insisting that a HRE is not accompanied with diastolic dysfunction or LV remodeling compared to those with normal response to exercise $[1,23,24]$.

While differences in modalities and intensities of exercise, or baseline characteristics of participants may be responsible for inconsistency in previous data, Shim et al. [25] provided an interesting possible explanation. In this study, central hemodynamic characters were assessed in individuals with HRE and compared to those with normal responses during exercise. Diverse central BP responses were observed in individuals: high pulse pressure amplification vs. low pulse pressure amplification after exercise. It implicates that a HRE is not always accompanied by elevation of central BP, which is a wellknown factor to target organ damage and future cardiovascular events. Therefore, a HRE would result in abnormal LV function and structural remodeling in presence of arterial stiffening (Fig. 1).

A HRE is generally conceived as a risk for future development of hypertension, evidenced by a substantial number of previous studies with either bicycle or treadmill exercise [11, 26]. Systolic BP measured during light to moderate exercise is shown to predict masked hypertension with high specificity in individuals with HRE [27]. However, current guideline does not recommend exercise testing as a screen test for prehypertension given the low predictive value [28]. A previous meta-analysis revealed that a HRE at moderate exercise workload increased cardiovascular outcomes (fatal or non-fatal myocardial infarction, stroke, or development of coronary artery disease)

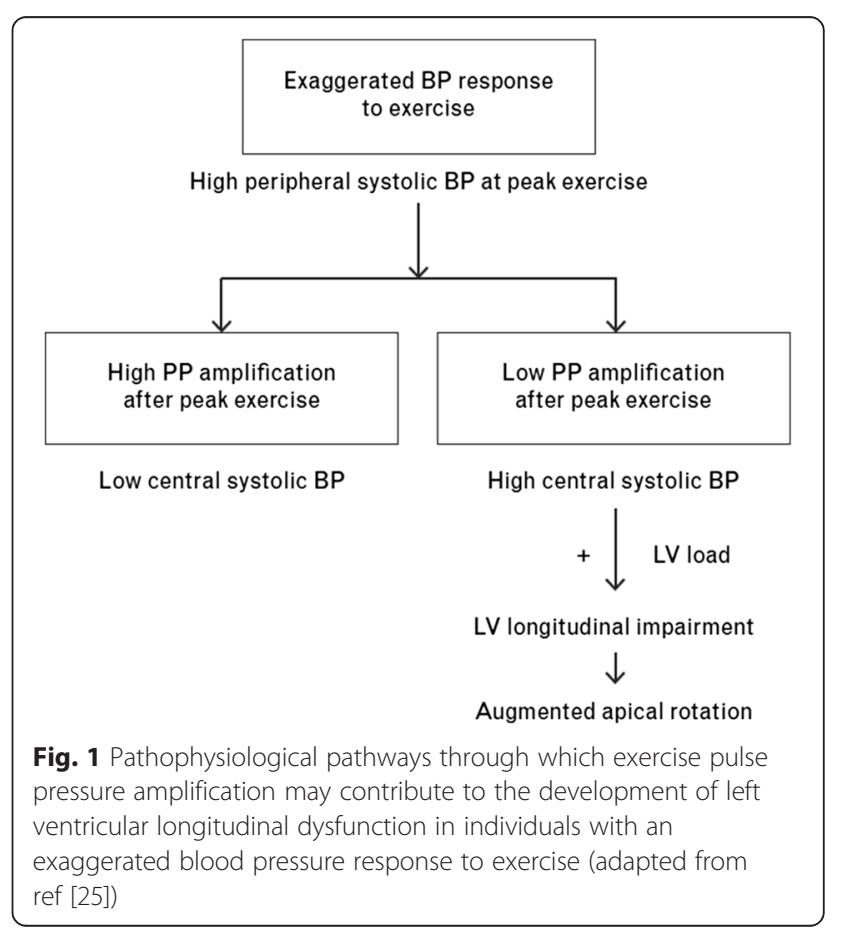


by $36 \%$ ( $95 \%$ CI, 1.02-1.38, $p=0.039)$ after adjustment for other cardiovascular risk factors [29]. In this study, every $10 \mathrm{mmHg}$ increase in systolic BP during exercise at moderate intensity was accompanied by a $4 \%$ increase in cardiovascular event and mortality independent of mode of exercise. It is interesting that prognostic value of $\mathrm{BP}$ during high work load was not as influential as BP during moderate work load. Although future studies are warranted, submaximal workload may better reflect daily ambulatory BP of participants, therefore, clinically more relevant than BP during high work load. Also, difficulties in measuring BP during high work load may have attributed to such results.

\section{Treatment}

As suggested by previous studies, exaggerated BP response to exercise is not a benign phenomenon, but it is still controversial whether to treat HRE in individuals without hypertension. Moreover, treatment strategy is still uncertain. Given previous data, angiotensin II is considered as the most important neurohormone affecting vascular and myocardial responses to exercise. Therefore, angiotensin receptor blocker or angiotensin converting enzyme inhibitor could be recommended as a treatment for individuals with HRE. Beta blocker could also be the drug of choice considering increased sympathetic tone during exercise. Currently, there is an ongoing clinical trial investigating efficacy of Fimasartan and Atenolol in hypertensive patients with HRE. Further results would provide insight to treatment strategy for HRE in individuals without hypertension.

\section{Conclusion}

A HRE is pathologic phenomenon and associated with functional and structural impairment of LV, future development of hypertension and increased cardiovascular event, although conflicting data exist due to diverse reponses to central hemodynamics, various methodologies, and different clinical characteristics of study population. Further consensus on definition and method to measure HRE may provide insightful information to clinicians.

\section{Abbreviations}

$B P$, blood pressure; HRE, hypertensive responses to exercise; LV, left ventricle; $\mathrm{NO}$, nitric oxide; RAAS, renin-angiotensin-aldosterone system.

\section{Acknowledgements}

Not applicable.

Funding

Not applicable.

Availability of data and materials

Not applicable.
Authors' contributions

DK mainly contributed in writing the manuscript. JH coordinated the manuscript, provided references and is the corresponding author. All authors read and approved the final manuscript.

\section{Competing interests}

The authors declare that they have no competing interests.

Consent for publication

Not applicable.

Ethics approval and consent to participate

Not applicable.

Received: 16 May 2016 Accepted: 20 July 2016

Published online: 26 July 2016

\section{References}

1. Shim CY, Ha JW, Park S, Choi EY, Choi D, Rim SJ, et al. Exaggerated blood pressure response to exercise is associated with augmented rise of angiotensin II during exercise. J Am Coll Cardiol. 2008;52(4):287-92.

2. Lauer MS, Pashkow FJ, Harvey SA, Marwick TH, Thomas JD. Angiographic and prognostic implications of an exaggerated exercise systolic blood pressure response and rest systolic blood pressure in adults undergoing evaluation for suspected coronary artery disease. J Am Coll Cardiol. 1995;26(7):1630-6.

3. Allison TG, Cordeiro MA, Miller TD, Daida H, Squires RW, Gau GT. Prognostic significance of exercise-induced systemic hypertension in healthy subjects. Am J Cardiol. 1999:83(3):371-5.

4. Tsumura K, Hayashi T, Hamada C, Endo G, Fujii S, Okada K. Blood pressure response after two-step exercise as a powerful predictor of hypertension: the Osaka Health Survey. J Hypertens. 2002;20(8):1507-12.

5. Manolio TA, Burke GL, Savage PJ, Sidney S, Gardin JM, Oberman A. Exercise blood pressure response and 5-year risk of elevated blood pressure in a cohort of young adults: the CARDIA study. Am J Hypertens. 1994;7(3):234-41.

6. Filipovsky J, Ducimetiere P, Safar ME. Prognostic significance of exercise blood pressure and heart rate in middle-aged men. Hypertension. 1992;20(3):333-9.

7. Fagard R, Staessen J, Thijs L, Amery A. Prognostic significance of exercise versus resting blood pressure in hypertensive men. Hypertension. 1991;17(4):574-8.

8. Fagard RH, Pardaens K, Staessen JA, Thijs L. Prognostic value of invasive hemodynamic measurements at rest and during exercise in hypertensive men. Hypertension. 1996:28(1):31-6.

9. Miyai N, Arita M, Morioka I, Miyashita K, Nishio I, Takeda S. Exercise BP response in subjects with high-normal BP: exaggerated blood pressure response to exercise and risk of future hypertension in subjects with highnormal blood pressure. J Am Coll Cardiol. 2000;36(5):1626-31.

10. Stewart KJ, Sung J, Silber HA, Fleg JL, Kelemen MD, Turner KL, et al. Exaggerated exercise blood pressure is related to impaired endothelial vasodilator function. Am J Hypertens. 2004;17(4):314-20.

11. Wilson MF, Sung BH, Pincomb GA, Lovallo WR. Exaggerated pressure response to exercise in men at risk for systemic hypertension. Am J Cardiol. 1990;66(7):731-6.

12. Tzemos N, Lim PO, Mackenzie IS, MacDonald TM. Exaggerated exercise blood pressure response and future cardiovascular disease. J Clin Hypertens. 2015:17(11):837-44

13. Thanassoulis G, Lyass A, Benjamin EJ, Larson MG, Vita JA, Levy D, et al. Relations of exercise blood pressure response to cardiovascular risk factors and vascular function in the Framingham Heart Study. Circulation. 2012;125(23):2836-43.

14. Galbo H. The hormonal response to exercise. Diabetes Metab Rev. 1986;1(4):385-408

15. Fallo F. Renin-angiotensin-aldosterone system and physical exercise. J Sports Med Phys Fitness. 1993;33(3):306-12.

16. Warner Jr JG, Metzger DC, Kitzman DW, Wesley DJ, Little WC. Losartan improves exercise tolerance in patients with diastolic dysfunction and a hypertensive response to exercise. J Am Coll Cardiol. 1999;33(6):1567-72.

17. Ozkor MA, Hayek SS, Rahman AM, Murrow JR, Kavtaradze N, Lin J, et al. Contribution of endothelium-derived hyperpolarizing factor to exerciseinduced vasodilation in health and hypercholesterolemia. Vasc Med. 2015;20(1):14-22.

18. Papavasileiou MV, Thomopoulos C, Antoniou I, Papadimitriou G, Seferou M, Makris TK. Impaired glucose metabolism and the exaggerated blood 
pressure response to exercise treadmill testing in normotensive patients. J Clin Hypertens (Greenwich). 2009;11(11):627-35.

19. Ha JW, Juracan EM, Mahoney DW, Oh JK, Shub C, Seward JB, et al. Hypertensive response to exercise: a potential cause for new wall motion abnormality in the absence of coronary artery disease. J Am Coll Cardiol. 2002:39(2):323-7.

20. Gottdiener JS, Brown J, Zoltick J, Fletcher RD. Left ventricular hypertrophy in men with normal blood pressure: relation to exaggerated blood pressure response to exercise. Ann Intern Med. 1990;112(3):161-6.

21. Molina L, Elosua R, Marrugat J, Pons S. Relation of maximum blood pressure during exercise and regular physical activity in normotensive men with left ventricular mass and hypertrophy. MARATHOM Investigators. Medida de la Actividad fisica y su Relacion Ambiental con Todos los Lipidos en el HOMbre. Am J Cardiol. 1999;84(8):890-3.

22. Takamura T, Onishi K, Sugimoto T, Kurita T, Fujimoto N, Dohi K, et al. Patients with a hypertensive response to exercise have impaired left ventricular diastolic function. Hypertens Res. 2008;31(2):257-63.

23. Mottram PM, Haluska B, Yuda S, Leano R, Marwick TH. Patients with a hypertensive response to exercise have impaired systolic function without diastolic dysfunction or left ventricular hypertrophy. J Am Coll Cardiol. 2004;43(5):848-53.

24. Lauer MS, Levy D, Anderson KM, Plehn JF. Is there a relationship between exercise systolic blood-pressure response and left-ventricular mass - the Framingham Heart-Study. Ann Intern Med. 1992;116(3):203-10.

25. Shim CY, Hong GR, Park S, Yang WI, Choi D, Chung N, Ha JW. Impact of central haemodynamics on left ventricular function in individuals with an exaggerated blood pressure response to exercise. J Hypertens. 2015;33(3):612-20.

26. Franz IW. Assessment of blood pressure response during ergometric work in normotensive and hypertensive patients. Acta Med Scand Suppl. 1982;670:35-47.

27. Schultz MG, Hare JL, Marwick TH, Stowasser M, Sharman JE. Masked hypertension is "unmasked" by low-intensity exercise blood pressure. Blood Press. 2011;20(5):284-9.

28. Le W, Mitiku T, Sungar G, Myers J, Froelicher V. The blood pressure response to dynamic exercise testing: a systematic review. Prog Cardiovasc Dis. 2008;51(2):135-60

29. Schultz MG, Otahal P, Cleland VJ, Blizzard L, Marwick TH, Sharman JE. Exercise-induced hypertension, cardiovascular events, and mortality in patients undergoing exercise stress testing: a systematic review and metaanalysis. Am J Hypertens. 2013;26(3):357-66.

\section{Submit your next manuscript to BioMed Central and we will help you at every step:}

- We accept pre-submission inquiries

- Our selector tool helps you to find the most relevant journal

- We provide round the clock customer support

- Convenient online submission

- Thorough peer review

- Inclusion in PubMed and all major indexing services

- Maximum visibility for your research

Submit your manuscript at www.biomedcentral.com/submit 